\title{
Speech production: Evidence for syntactically and phonologically determined units
}

\author{
JAMES R. LACKNER and KENNETH B. LEVINE \\ Brandeis University, Waltham, Massachusetts 02154
}

\begin{abstract}
The durational accuracy with which subjects can speak syntactically structured strings of words was compared with their accuracy in speaking word lists. These measurements underscored the great temporal precision of the human articulatory mechanism which appears to be the most precisely controlled movement system of the human body. Evidence is presented that when a syntactically structured message is being spoken, the centrally programmed innervational units involved in its articulatory implementation are greater in size and complexity than when a word list is being spoken.
\end{abstract}

The serial coordination of the vocal apparatus during the production of speech is a process of great intricacy and precision. Recently, MacNeilage (1970) and Sussman (1972) have described the tremendous complexity involved in coordinating the various parts of the vocal tract in the course of creating the elegant spatial and temporal acoustic patterns characteristic of speech sounds. Ladefoged's studies (1967) have emphasized how precise the control of respiratory outflow is during speech production and have underscored the sophisticated control problem involved in maintaining the interleaved pattern of activation and coactivation of the many muscle groups that are involved in the regulation of air outflow from the lungs through the vocal tract.

Although the moment-to-moment physical configurations of the vocal apparatus during the pronunciation of individual speech sounds within segmental contexts are now reasonably well known (Perkell. 1969), little is known about ongoing speech production in terms of the size or character of the central programming or "innervational units" used to drive the vocal apparatus when larger stretches of speech are being produced. Some indirect evidence for a linguistic contribution to the determination of these units has been derived from situations in which the speech production process went awry and slips of the tongue occurred. MacKay (1970) and Fromkin (1971) have observed that such slips may involve

This study was supported by grants from the Rosenstiel Biomedical Sciences Foundation, the Alfred P. Sloan Foundation, the Spencer Foundation, and NIH Grant MH24433. We wish to thank Ronald Calvanio, Donald Erwin, Judith Kroll, and Joel Ventura for statistical assistance. Hubert Dolezal contributed many valuable suggestions that improved the manuscript. Reprint requests should be sent to $J$. R. Lackner, Department of Psychology, Brandeis University, Waltham, Massachusetts 02154. Dr. Lackner is also at the Department of Psychology, Massachusetts Institute of Technology, Cambridge, Massachusetts 02139. single distinctive features, phones, syllables, words, and occasionally phrases. The existence of errors involving these linguistic constructs argues for their representation or participation at some levels of organization in the speech production process, although it does not argue necessarily for a supraword level of organization at the final stage of speech production where the scope and character of the innervation commands issued to the vocal apparatus are determined. In fact, in spoonerisms involving morpheme or word interchanges, the switched items generally are supplied with the inflectional endings appropriate to their new environment (see Fromkin, 1971); consequently, the interchange must occur at a level of representation before the coding into a final articulatory schema has been achieved because otherwise only strict non-context-sensitive interchanges would be expected.

Further evidence for control units in speech production at a supraword level is provided in a recent experiment by Shattuck and Lackner (in press) in which subjects were required to shadow sentences and lists of words that were presented at different rates. (The word lists contained the same sets of words as the sentences but in reverse sequence.) At the higher rates of presentation, 3, 4, 5, or 6 words/sec, subjects could shadow sentences much more accurately than word lists. All subjects reported that they could hear and understand the incoming words from both the lists and the sentences easily but, in the case of the word lists, were unable to repeat the words fast enough. Shattuck and Lackner also found that subjects who had memorized sentences and lists of words constructed from the same sentences could always say the sentences more rapidly than the corresponding word lists, regardless of how much the word lists had been practiced; moreover, subjects who were able to impose a rhythmic intonation on the word lists could saly them faster than the other subjects. 
Such observations suggest that the presence of syntactic structure facilitates speech production. The experimental work reported here is an attempt to determine whether this facilitation results because the planning unit in speech production is of greater size and complexity when syntax is present in that it includes the innervation plan for sequences greater than a word in length.

Our approach was to measure the temporal accuracy with which subjects could speak sentences and strings of words when they are attempting to repeat them as exactly as possible. Subjects performed under two conditions: once while receiving normal auditory feedback from their speech and once while receiving a masking noise in the ears. Our hypothesis was that subjects would be able to repeat a sentence with greater durational pręcision than they would a list of the same words in a scrambled order. We expected the mean durations of the repetitions of the individual sentences to be shorter than those of the corresponding word lists and the relative, as well as the absolute, temporal precision of the sentences to be greater than that of the word lists-especially for longer stimulus lengths. Several studies (Fairbanks, 1954, 1955; Yates, 1963) have reported that delaying or masking auditory feedback significantly alters speech production, causing increases in fundamental frequency, increases in intensity, and increases in overall duration. In our masking condition, we expected the mean duration and accuracy of repetition of sentences to be less affected than that of lists.

The rationale for these expectations is as follows. If the centrally determined "innervational sequences" in speech production are larger when syntax is present, encompassing the articulation of more than one word or a phrase, then the temporal variance among repeated instances of a particular sentence should be less than among repeated instances of the same set of words in a nonsyntactic order: the variance of the repeated word lists should be close to the sum of the variances of the words of the list spoken in isolation; by contrast, the variance of the repeated sentences should be less than the sum of the variances in speaking the constituent words because, according to our hypothesis, the words in a sentence frame are not implemented wholly as individual entities.

Since masking of auditory feedback (Ringel \& Steer, 1963) interferes with fine control of the duration of speech sounds, this interference should be greatest for word lists in which each individual member should be subject to distortion during production, and should be least for sentences in which the interference should operate on a programming unit of greater size and temporal refinement. Our conditions also include a situation in which subjects were required to impose a rhythmic structure on word lists as they repeated them since we thought, in keeping with the observations of Shattuck and Lackner (in press) that the imposition of any supraword structure, syntactic or prosodic, might contribute to shorter duration and increased accuracy in speech production.

\section{METHOD}

\section{Subjects}

Eight Brandeis students volunteered for paired participation. All were native speakers of English and were without known speech or hearing defects.

\section{Stimuli}

Normal, active English sentences, 5, 10, and 15 words in length, were constructed; no attempt was made to equate the words of the sentences for syllable length. Ten stimuli were prepared at each of these lengths. A corresponding word list was prepared for each sentence by rearranging the words of the sentence until they no longer formed any syntactic units. Individual stimuli were typed on $3 \times 5$ in. cards to be given to the subjects.

\section{Experimental Procedure}

The experiment was run in 10 separate sessions for each subject. At least 2 days prior to a session, the subject was given index cards containing the stimulus items for the upcoming session and asked to study them until he could repeat the stimuli without looking at the cards. For each session, the subject was given two sentences and two word lists at each of the three stimulus lengths. The word lists in each session were always constructed from sentences other than those used in that particular experimental session. Subject to this constraint, the selection of sentences and word lists for a particular session was randomized for individual subjects.

Within a given experimental session, the subject was required to speak each of the stimuli (sentence and word list) five times in succession at a conversational rate followed by five repetitions at a rapid but still intelligible rate. The subject was instructed to make successive repetitions of a stimulus as identical as he possibly could. The word lists had to be read in two ways: with a list intonation and with an imposed rhythm, each at the two rates.

The order of the items for a particular session was determined in the following manner: all items of the same structural category (i.e., syntax, word list spoken with rhythm, word list spoken with list intonation) were grouped together. The order of these categories was randomized for each session. Within each category, the rapid rendition of a particular stimulus always immediately followed its conversational repetitions. The subject did not know prior to the session what the speaking orders of the stimuli would be.

All subjects first participated in five experimental sessions in which they were permitted normal auditory feedback while speaking and then returned for five additional sessions identical to the previous ones, with the exception that while speaking the subject was wearing headphones that delivered white noise $(90 \mathrm{~dB}$ SPL re .0002 dynes $/ \mathrm{cm}^{2}$ ) to his ears. The later sessions were identical to the earlier ones for each subject. Sessions were always separated by at least 1 to 2 days.

During an experimental session, the subject was seated in a sound-insulated booth and spoke into a microphone located approximately $12 \mathrm{in}$. in front of his mouth. The subject was told that if he was not satisfied with a particular repetition of a stimulus, i.e., if he felt it was not as perfect as he could make it, simply to say "scratch that one" and to repeat the stimulus until he was satisfied.

\section{Scoring}

The magnetic tape recordings of each subject's experimental sessions were transduced into graphic records by means of an inkwriting polygraph. Prior to being led into the polygraph, the 
output of the tape recorder was passed through a full-wave rectification circuit. Rectification of the signal made it easier to score the graphic records because pen deflection was larger and always in the same direction from the base line; consequently, it was easier to locate the onset and offset of stimuli.

The polygraph chart speed was set at $30 \mathrm{~mm} / \mathrm{sec}$ for the transcriptions. our estimated accuracy of measurement is $\pm .5 \mathrm{~mm}$, i.e., $\pm 17 \mathrm{msec}$, or less. For each experimental stimulus, the first four of its repeated instances were measured; the fifth repetition was not measured to avoid the possibility that the subject might reduce his attention to the task and "rush" the final repetition. Scoring was done without foreknowledge of whether a particular trace was that of a sentence or word list.

\section{RESULTS}

Mean syllabic duration was calculated for all experimental stimuli of a particular type and length across subjects for each condition of production. Syllabic duration was chosen as the unit of analysis because the sentence (and accordingly, word list) stimuli of a particular length in words did not always have the same number of syllables. These results are presented in Table 1; standard deviations were also calculated for each condition and are presented in Table 2.

Since there were considerable differences in mean syllabic duration for the different stimulus types (sentences, lists) and lengths, a measure of variability was required that would reflect the relative variability of a particular condition given the mean syllable duration associated with it. The coefficient of variation, e.g., the standard deviation divided by the mean, was chosen as appropriate. Table 3 presents the coefficients of variation for the various experimental situations.

To determine the significance of the differences in mean syllabic duration among the experimental conditions, a four-way analysis of variance was conducted. The results of this analysis are summarized in Table 4. All main effects were significant at the .001 level with the exception of the masking vs nonmasking comparison, which was insignificant. Further analysis of the significant main effects was conducted through the application of Student-Newman-Keuls tests. These tests revealed that the influence of stimulus length was confined to a significant decrease $(p<.01)$ in syllabic duration for stimuli 10 and 15 words in length compared to the stimuli 5 words in length. The contribution of structure, syntactic or intonational, appeared as shorter syllabic durations for sentences and word lists spoken rhythmically compared to lists spoken with list intonation $(\mathrm{p}<.01)$ and as shorter syllabic durations for sentences compared to lists spoken with rhythmic intonation $(\mathrm{p}<.05)$. The rate of speech variable (conversational vs rapid) was significant $(p<.001)$ for all comparisons.

Four interactions occurred: (1) stimulus length vs.
Table 1

Mean Syllabic Duration (Milliseconds)

\begin{tabular}{|c|c|c|c|c|c|}
\hline & . & $\begin{array}{l}\text { Audit } \\
\text { Unm }\end{array}$ & $\begin{array}{l}\text { ory Feed } \\
\text { sked }\end{array}$ & $\begin{array}{r}\mathrm{Ma} \\
\mathrm{Mack}\end{array}$ & $\begin{array}{l}\text { tion } \\
\text { ed }\end{array}$ \\
\hline & & & Rate of & Speakıng & \\
\hline $\begin{array}{r}\text { Resp } \\
\text { and }\end{array}$ & $\begin{array}{l}\text { se Type } \\
\text { ength }\end{array}$ & $\begin{array}{l}\text { Conver- } \\
\text { sational }\end{array}$ & Rapid & $\begin{array}{l}\text { Conver- } \\
\text { sational }\end{array}$ & Rapid \\
\hline $\begin{array}{c}5 \\
\text { Words }\end{array}$ & $\begin{array}{l}\text { Sentence } \\
\text { Rhythm } \\
\text { List }\end{array}$ & $\begin{array}{l}225 \\
242 \\
341\end{array}$ & $\begin{array}{l}159 \\
172 \\
203\end{array}$ & $\begin{array}{l}229 \\
248 \\
364\end{array}$ & $\begin{array}{l}157 \\
170 \\
203\end{array}$ \\
\hline $\begin{array}{c}10 \\
\text { Words }\end{array}$ & $\begin{array}{l}\text { Sentence } \\
\text { Rhythm } \\
\text { List }\end{array}$ & $\begin{array}{l}188 \\
236 \\
334\end{array}$ & $\begin{array}{l}140 \\
170 \\
206\end{array}$ & $\begin{array}{l}189 \\
231 \\
337\end{array}$ & $\begin{array}{l}136 \\
159 \\
192\end{array}$ \\
\hline $\begin{array}{c}15 \\
\text { Words }\end{array}$ & $\begin{array}{l}\text { Sentence } \\
\text { Rhy thm } \\
\text { List }\end{array}$ & $\begin{array}{l}178 \\
241 \\
359\end{array}$ & $\begin{array}{l}130 \\
174 \\
210\end{array}$ & $\begin{array}{l}178 \\
227 \\
350\end{array}$ & $\begin{array}{l}126 \\
156 \\
198\end{array}$ \\
\hline
\end{tabular}

Table 2

Mean Syllabic Standard Deviation (Milliseconds)

\begin{tabular}{|c|c|c|c|c|c|}
\hline & & $\begin{array}{l}\text { Audi } \\
\text { Unm }\end{array}$ & $\begin{array}{l}\text { ry Feed } \\
\text { ked }\end{array}$ & $\begin{array}{r}\text { ack Cons } \\
\text { Mas }\end{array}$ & $\begin{array}{l}\text { tion } \\
\text { ed }\end{array}$ \\
\hline & & & Rate of & Speaking & \\
\hline $\begin{array}{l}\text { Resp } \\
\text { and }\end{array}$ & $\begin{array}{l}\text { se Type } \\
\text { ength }\end{array}$ & $\begin{array}{l}\text { Conver- } \\
\text { sational }\end{array}$ & Rapid & $\begin{array}{l}\text { Conver- } \\
\text { sational }\end{array}$ & Rapid \\
\hline $\begin{array}{c}5 \\
\text { Words }\end{array}$ & $\begin{array}{l}\text { Sentence } \\
\text { Rhythm } \\
\text { List }\end{array}$ & $\begin{array}{l}49 \\
55 \\
88\end{array}$ & $\begin{array}{l}34 \\
38 \\
47\end{array}$ & $\begin{array}{l}48 \\
56 \\
86\end{array}$ & $\begin{array}{l}32 \\
36 \\
45\end{array}$ \\
\hline $\begin{array}{c}10 \\
\text { Words }\end{array}$ & $\begin{array}{l}\text { Sentence } \\
\text { Rhythm } \\
\text { List }\end{array}$ & $\begin{array}{l}28 \\
43 \\
69\end{array}$ & $\begin{array}{l}20 \\
25 \\
36\end{array}$ & $\begin{array}{l}30 \\
35 \\
55\end{array}$ & $\begin{array}{l}20 \\
21 \\
29\end{array}$ \\
\hline $\begin{array}{c}15 \\
\text { Words }\end{array}$ & $\begin{array}{l}\text { Sentence } \\
\text { Rhythm } \\
\text { List }\end{array}$ & $\begin{array}{l}17 \\
30 \\
66\end{array}$ & $\begin{array}{l}12 \\
21 \\
34\end{array}$ & $\begin{array}{l}21 \\
25 \\
47\end{array}$ & $\begin{array}{l}12 \\
16 \\
24\end{array}$ \\
\hline
\end{tabular}

Table 3

Syllabic Coefficient of Variation

\begin{tabular}{|c|c|c|c|c|c|}
\hline & & $\begin{array}{l}\text { Audi } \\
\text { Unm }\end{array}$ & $\begin{array}{l}\text { ry Fet } \\
\text { ked }\end{array}$ & $\begin{array}{r}\text { back Con } \\
\mathrm{Ma}\end{array}$ & $\begin{array}{l}\text { ition } \\
\text { ed }\end{array}$ \\
\hline & & & Rate & Speakin & \\
\hline $\begin{array}{r}\text { Resp } \\
\text { and }\end{array}$ & $\begin{array}{l}\text { se Type } \\
\text { ength }\end{array}$ & $\begin{array}{l}\text { Conver- } \\
\text { sational }\end{array}$ & Rapid & $\begin{array}{l}\text { Conver- } \\
\text { sational }\end{array}$ & Rapid \\
\hline $\begin{array}{c}5 \\
\text { Words }\end{array}$ & $\begin{array}{l}\text { Sentence } \\
\text { Rhythm } \\
\text { List }\end{array}$ & $\begin{array}{l}.218 \\
.227 \\
.258\end{array}$ & $\begin{array}{l}.214 \\
.221 \\
.232\end{array}$ & $\begin{array}{l}.210 \\
.226 \\
.236\end{array}$ & $\begin{array}{l}.204 \\
.212 \\
.222\end{array}$ \\
\hline $\begin{array}{c}10 \\
\text { Words }\end{array}$ & $\begin{array}{l}\text { Sentence } \\
\text { Rhythm } \\
\text { List }\end{array}$ & $\begin{array}{l}.149 \\
.182 \\
.206\end{array}$ & $\begin{array}{l}.143 \\
.147 \\
.175\end{array}$ & $\begin{array}{l}.159 \\
.152 \\
.163\end{array}$ & $\begin{array}{l}.147 \\
.132 \\
.151\end{array}$ \\
\hline $\begin{array}{c}15 \\
\text { Words }\end{array}$ & $\begin{array}{l}\text { Sentence } \\
\text { Rhythm } \\
\text { List }\end{array}$ & $\begin{array}{l}.096 \\
.125 \\
.184\end{array}$ & $\begin{array}{l}.092 \\
.121 \\
.162\end{array}$ & $\begin{array}{l}.118 \\
.110 \\
.134\end{array}$ & $\begin{array}{l}.095 \\
.103 \\
.121\end{array}$ \\
\hline
\end{tabular}

structure ( $\mathrm{p}<.001)$; (2) stimulus length vs. rate $(\mathrm{p}<.05) ; \quad(3)$ structure vs. rate $(\mathrm{p}<.01)$, and (4) stimulus length vs. feedback $(p<.001)$. These interactions were further analyzed with StudentNewman-Keuls tests. The stimulus length vs. 
Table 4

Syllabic Duration: Analysis of Variance

\begin{tabular}{ccccc}
\multicolumn{1}{c}{$\begin{array}{c}\text { Mean } \\
\text { Source }\end{array}$} & Square & $\begin{array}{c}\text { Mean Square } \\
\text { Error }\end{array}$ & df & F \\
\cline { 1 - 2 } Item Length & & & & \\
A & $8.137 \times 10^{3}$ & $3.789 \times 10^{2}$ & 2,14 & $21.49 \dagger$ \\
Amount of Structure & & & \\
B & $2.771 \times 10^{5}$ & $1.215 \times 10^{4}$ & 2,14 & $22.81 \dagger$ \\
Rate of Speech & & & \\
C & $5.938 \times 10^{5}$ & $9.255 \times 10^{3}$ & 1,7 & $64.16 \dagger$ \\
Feedback & & & & \\
D & $6.440 \times 10^{2}$ & $1.635 \times 10^{3}$ & 1,7 & .39 \\
AB & $3.825 \times 10^{3}$ & $1.970 \times 10^{2}$ & 4,28 & $19.42 \dagger$ \\
AC & $8.709 \times 10^{2}$ & $1.808 \times 10^{2}$ & 2,14 & $4.82^{*}$ \\
AD & $1.290 \times 10^{3}$ & $9.921 \times 10^{1}$ & 2,14 & $13.00 \dagger$ \\
BC & $5.442 \times 10^{4}$ & $8.304 \times 10^{3}$ & 2,14 & $6.55^{* *}$ \\
BD & $2.906 \times 10^{2}$ & $1.283 \times 10^{3}$ & 2,14 & .23 \\
CD & $1.341 \times 10^{3}$ & $1.679 \times 10^{3}$ & 1,7 & .80 \\
ABC & $2.833 \times 10^{2}$ & $1.950 \times 10^{2}$ & 4,28 & 1.45 \\
ABD & $2.256 \times 10^{2}$ & $1.174 \times 10^{2}$ & 4,28 & 1.92 \\
ACD & $1.123 \times 10^{2}$ & $8.906 \times 10^{1}$ & 2,14 & 1.26 \\
BCD & $1.486 \times 10^{2}$ & $1.040 \times 10^{3}$ & 2,14 & .14 \\
ABCD & $5.277 \times 10^{1}$ & $7.118 \times 10^{1}$ & 4,28 & .74 \\
\hline
\end{tabular}

Note-Item length $=5,10,15$ words; amount of structure $=$ sentence, rhythm, list; rate of speech = conversational, rapid, feedback = masking, no masking.

*Significant at $p<.05$ but not $p<.01$

**Significant at $p<.01$ but not $p<.001$

tSignificant at $p<.001$

structure interaction resulted from a decrease in mean syllabic duration for sentences 10 words vs. 5 words in length $(\mathrm{p}<.01)$, for sentences 15 words vs. 5 words in length $(\mathrm{p}<.01)$, and for lists 10 words vs. 5 words in length $(\mathrm{p}<.01)$. A decreased mean syllabic duration $(p<.01)$ for stimuli, spoken at the conversational rate, 10 words vs. 5 words in length, was the basis for the second interaction. The structure vs. rate of speech interaction resulted from four components: at the conversational rate, mean syllabic duration was shorter for lists spoken with rhythmic intonation compared to lists with list intonation $(\mathrm{p}<.01)$ and mean syllabic duration was also shorter for sentences compared to lists with list intonation $(\mathrm{p}<.01)$; for the rapid rates of speaking, the mean syllabic duration was shorter for the sentences $(p<.05)$ and the lists with thythm $(p<.05)$ in comparison to the lists with list intonation. The final interaction, stimulus length vs. feedback, resulted from two sources: mean syllabic duration was shorter for the 5-word stimuli when the white noise mask was absent $(\mathrm{p}<.05)$ and mean syllabic duration was shorter for 15 -word stimuli when the white noise was present $(\mathrm{p}<.05)$.

A four-way analysis of variance was also performed on the coefficients of variation for the experimental conditions. The results of this analysis are presented in Table 5. All main effects were significant and accordingly were further analyzed by means of Student-Newman-Keuls tests. As stimulus length increased, the coefficient of variation decreased for all kinds of stimuli $(p<.01)$. The influence of structure
Table 5

Coefficient of Variation: Analysis of Variance

\begin{tabular}{|c|c|c|c|c|}
\hline Source & $\begin{array}{l}\text { Mean } \\
\text { Square }\end{array}$ & $\begin{array}{c}\text { Mean Square } \\
\text { Error }\end{array}$ & df & $\mathrm{F}$ \\
\hline \multicolumn{5}{|c|}{ Item Length } \\
\hline A & $2.614 \times 10^{5}$ & $1.556 \times 10^{3}$ & 2,14 & $167.99 \dagger$ \\
\hline \multicolumn{5}{|c|}{ Amount of Structure } \\
\hline B & $2.880 \times 10^{4}$ & $2.023 \times 10^{3}$ & 2,14 & $14.24 \dagger$ \\
\hline \multicolumn{5}{|c|}{ Rate of Speech } \\
\hline $\mathrm{C}$ & $1.462 \times 10^{4}$ & $8.242 \times 10^{2}$ & 1,7 & $17.74 * *$ \\
\hline \multicolumn{5}{|l|}{ Feedback } \\
\hline D & $1.521 \times 10^{4}$ & $2.193 \times 10^{3}$ & 1,7 & $6.93^{*}$ \\
\hline $\mathrm{AB}$ & $2.153 \times 10^{3}$ & $8.508 \times 10^{2}$ & 4,28 & 2.53 \\
\hline $\mathrm{AC}$ & $2.412 \times 10^{2}$ & $2.642 \times 10^{2}$ & 2,14 & .91 \\
\hline $\mathrm{AD}$ & $5.144 \times 10^{2}$ & $8.666 \times 10^{2}$ & 2,14 & .59 \\
\hline $\mathrm{BC}$ & $8.912 \times 10^{2}$ & $7.418 \times 10^{2}$ & 2,14 & 1.20 \\
\hline $\mathrm{BD}$ & $6.221 \times 10^{3}$ & $1.213 \times 10^{3}$ & 2,14 & $5.13^{*}$ \\
\hline $\mathrm{CD}$ & $2.161 \times 10^{2}$ & $6.750 \times 10^{2}$ & 1,7 & .32 \\
\hline $\mathrm{ABC}$ & $4.125 \times 10^{2}$ & $3.241 \times 10^{2}$ & 4,28 & 1.27 \\
\hline $\mathrm{ABD}$ & $1.750 \times 10^{3}$ & $1.098 \times 10^{3}$ & 4,28 & 1.59 \\
\hline $\mathrm{ACD}$ & $3.131 \times 10^{2}$ & $3.341 \times 10^{2}$ & 2,14 & .94 \\
\hline $\mathrm{BCD}$ & $3.689 \times 10^{2}$ & $3.684 \times 10^{2}$ & 2,14 & 1.00 \\
\hline $\mathrm{ABCD}$ & $1.212 \times 10^{2}$ & $6.268 \times 10^{2}$ & 4,28 & .19 \\
\hline
\end{tabular}

*Significant at $p<.05$ but not $p<.01$

${ }^{* *}$ Significant at $p<.01$ but not $p<.001$

tSignificant at $p<.001$

appeared at all stimulus lengths as a decreased variability of the sentences and lists with rhythmic intonations compared to the lists with list intonation $(\mathrm{p}<.01)$. The coefficient of variation decreased at the faster rate of speaking for all combinations ( $p<.01$ ), and also decreased when the white noise mask was present $(\mathrm{p}<.05)$.

An interaction occurred between structure and masking $(p<.01)$. The Student-Newman-Keuls analysis of this interaction revealed that the coefficient of variation was significantly smaller for lists spoken with list intonation $(\mathrm{p}<.01)$ and lists spoken with rhythmic intonation $(p<.05)$ when the white noise mask was present.

\section{DISCUSSION}

The durational accuracy with which individual subjects can repeat particular sentence or list stimuli is not fully apparent in the results section because the tables present mean syllabic durations and standard deviations across subjects and there are considerable differences in mean sentence and list durations from subject to subject. However, a look at the performance of a typical subject repeating a 15-word sentence, at the rapid rate, reveals that his repetitions may have a mean duration over 3,000 msec and a standard deviation less than our accuracy of measurement, i.e., less than $17 \mathrm{msec}$. A word list, 15 words in length, may be repeated with a mean duration over $4,700 \mathrm{msec}$ and a standard deviation of 
approximately $120 \mathrm{msec}$. The precision of the vocal apparatus in performing feats of such remarkable timing must surpass that of the oculomotor system which controls eye movements. Previously, saccadic eye movements to peripheral visual targets were thought to be the most precisely controlled movements possible (Bender, 1964), but recent evidence obtained by Becker indicates that there is considerable variation in the latency and amplitude of saccadic eye movements to the same peripheral targets; generally the eyes undershoot or overshoot and corrective saccades are required to bring them onto target (see Becker, in Dichgans \& Bizzi, 1972). Consequently, the temporal variation in the time required to bring a peripheral target into the fovea is quite large, ranging from a minimum of approximately $200 \mathrm{msec}$ to a maximum of $500 \mathrm{msec}$ after stimulus onset; and the initial error in extent of the first saccade is often over $20 \%$ for target positions more than $15^{\circ}$ from the fixation point. Since the muscles of the tongue are second only to the extracular eye muscles in the density of their neural innervation (Silvernan, 1961), tongue movements of grealt precision and temporal accuracy are to be expected; however, our observations leave little doubt that the temporal precision of the entire vocal apparatus, involving many muscles and body parts, surpasses that of any other movement system of the human body (see Woodworth, 1899, for information on the accuracy of timing of limb movements).

In 1937, Hudgins and Stetson measured the maximum rate at which different articulatory movements could be performed during repetitions of particular syllables and found that the average number of movements possible per second varied from 8.2 for the tongue to 6.7 for the velum and the lips. These values correspond to mean durations of from 120 to $150 \mathrm{msec}$. In the present study, 15-word sentences spoken at the rapid pace had a mean syllabic duration of $130 \mathrm{msec}$ and the word lists spoken at the rapid pace had a mean syllabic duration of $178 \mathrm{msec}$. It should be emphasized that our subjects were not speaking at their fastest possible rates but were speaking slowly enough to maintain precise articulation and to avoid any slurring of words. All subjects were capable of saying the sentences and the word lists at considerably faster rates, although the sentences could always be spoken at fister maximal rates than the word lists (see also Shattuck \& Lackner, in press).

Hudgins and Stetson's rates were obtained with repetition of the same item; the rates reported here were obtained in situations in which the speakers never repeated the same syllable twice in a row. If the rates Hudgins and Stetson obtained in number of movemonts per second for the various parts of the vocal apparatus (lips, 6.7; jaw, 7.3; back of tongue,
7.1 ; tip of tongue, 8.2 ; velum, 6.7) are averaged, then a mean syllable duration of $140 \mathrm{msec}$ is derived. This value is the fastest average rate at which individual syllables could be expected to be produced repetitively in isolation, although it should be possible to produce a sequence of different syllables at slightly faster rates because of coarticulation effects which would operate across syllable boundaries as well as segments within words (Brosnahan \& Malmberg, 1970). It should be noted, however, that the average syllabic duration of the 10- and 15-word sentences spoken at the rapid rate was less than $140 \mathrm{msec}$, whereas the average syllabic duration of the word lists was always greater than this value.

Coarticulation would contribute to faster production and to increased accuracy of syllables within individual words. But the fact that the speed and accuracy of production of words within sentential contexts is always greater than that of words in nonsentential contexts implies that when different syllables are being sequentially produced as parts of words in sentences, there is interleaving of the movements of the vocal apparatus: vocal tract configurations necessary for the beginning of the next word in line are being neurologically implemented (i.e., the neural commands are being sent to the appropriate muscles) before the completion of the final syllable of the word currently being spoken. Thus, in the case of sentences, the final units of production control seem to encompass more than the articulatory program for a single word.

Further support for our claims arises from the observation that the coeflicients of variation were always significantly smaller for the sentences than for the word lists spoken with list intonation. As mentioned earlier, we predicted this outcome since we assumed that if the individual words of the sentences were not being separately and independently articulated but were being produced as part of a larger syntactically determined unit, then the relative durational variations of the repetitions of the sentences should be less than the durational variations of the repetitions of the corresponding word lists.

In this context, it should be recalled that performance of subjects was significantly more rapid and more accurate when speaking word lists rhythmically instead of with list intonation. Thus, as we had expected, the presence of structure in the form of a rhythmic intonation pattern, i.e., a supraword prosodic contour, contributed markedly to the speed and precision with which strings of words could be spoken. Nevertheless, the presence of syntactic as well as prosodic structure was always more effective then prosodic intonation alone in producing precise control of articulation. ${ }^{1}$ The significant decreases in both mean syllabic durations and coefficients of variation for the sentences (under all conditions) as sentence length increased from 5 to 10 or 5 to 15 words 
underscore the increased contribution of structure as stimulus length exceeds the traditional short-term memory span; these decreases occurred (significantly) only for the sentence stimuli.

Since the completion of the present study, our attention has been called to a monograph by Kozhevnikov and Chistovich (1965), in which measurements similar to our rate measurements with sentence stimuli had been conducted for identical theoretical reasons. Kozhevnikov and Chistovich found that the relative durations of syllables within the same sentence decrease pari passu as the sentence is spoken at faster and faster rates. From this observation, and others on relative accuracy, they concluded that speech production involves suprasyllabic levels of organization in the motor output.

As mentioned previously, several investigators (Black, 1951; Fairbanks, 1955; Lee, 1950; Ringel \& Steer, 1963) have reported that mean syllabic duration and total phonation time increase under conditions involving masked or delayed auditory feedback. In all of these experiments, subjects were required to read prose passages or other forms of syntactically structured material. Our results on the production of sentences by subjects exposed to masking noise do not agree with these earlier reports on the consequences of masking auditory feedback: neither mean syllabic duration nor overall phonation time was significantly affected. The mean syllabic duration of the lists read with rhythm and the lists read with list intonation also were not affected by the white noise mask. Only the coefficient of variation of the word lists (both the rhythm and the list intonation conditions) was affected by the presence of the white noise mask, and it decreased.

In the past, the deleterious effect of a masking noise on the timing of speech acts has been used to argue that speech production is dependent on a closed-loop, feedback control system rather than on an open-loop system in which the sensory consequences of a particular activity are not monitored during its execution. In a closed-loop system, sensory information about the ongoing configuration of a particular speech activity is used to achieve a more precise and stable control of that act (Fairbanks, 1954; MacNeilage, 1970; Sussman, 1972). Our observations are not totally inconsistent with the closed-loop theory, but they do suggest that the more information subjects have available with regard to what they are going to say next, the less important is auditory feedback (see also Lackner, 1974). In the present study, subjects knew the stimuli they were going to repeat-they did not read them as subjects have always done in the earlier experiments-and were impervious to masking of their auditory feedback. The decrease in coefficient of variation for the lists is probably attributable to a practice effect which aids the production of the lists but not that of the sentences; such a differential effect of practice for sentences and lists has already been reported by Shattuck and Lackner (in press).

From the pattern of results described here and the observations of Kozhevnikov and Chistovich (1965), we may conclude that the presence of syntactic structure facilitates the production of speech by increasing the size and complexity of the control patterns that are used to mobilize the vocal apparatus. The inconsequential effects produced by masking subjects' auditory feedback while they repeated known sequences can be taken to imply that auditory feedback control of vocalization may only be a significant factor when subjects are speaking slowly and either do not know what they want to say next or what they are going to be required to read next.

\section{REFERENCES}

Bender, M. B. (Ed.) The oculomotor system. New York: Hoeber, 1964

Dichgans, J., \& Bizzi, E. Cerebral control of eye movements and motion perception. Basel: Karger, 1972.

BLACK, J. The effects of delayed sidetone upon vocal rate and intensity. Journal of Speech and Hearing Disorders, 1951, 16. 56-60.

Brosnahan, L. F., \& Malmberg, B. Introduction to phonetics. Cambridge: Heffer, 1970.

Fairbanks. G. Systematic research in experimental phonetics: I. A theory of the speech meebanisn as a servosystem. Journal of Speech and Hearing Disorders, 1954, 19, 133-139.

Fairbanks, G. Selective vocal effects of delayed auditory feedback. Journal of Speech and Hearing Disorders, 1955, 20, 333-345.

Fromkin, V. The nonanomalous nature of anomalous utterances. Language, 1971, 47, 27-52.

Hudgins, C., \& Stetson, R. Relative speed of articulatory movements. Archives Néerlandaises de Phonétique Expérimentale, 1937, 13, 85-95.

Kozhevnixov, V. A., \& Chistovich, L. A. Speech: Articulation and perception. JPRS 30,543. Washington: U.S. Department of Commerce, 1965.

LACKNER, J. Speech production: Evidence for corollary-discharge stabilization of perceptual mechanisms. Perceptual and Motor Skills, 1974, 39, 899-902

LADEFOGED, P. Three areas of experimental phonetics. London: Oxford University Press, 1967.

LEE, B. S. Effects of delayed speech feedback. Journal of the Acoustical Society of America, 1950, 22, 824-826.

MACKAY, D. G. Spoonerisms: The structure of errors in the serial order of speech. Neuropsychologia, 1970, 8, 323-350.

MACNEILAGE, P. F. Motor control of serial ordering of speech. Psychological Review, 1970, 77, 182-196.

Perkele, J. Physiology of speech production: Results and implications of a quantitative cineradiographic study. Cambridge, Mass: M.I.T. Press, 1969.

Ringel, R. L., \& STEER, M. D. Some effects of tactile and auditory alterations of speech output. Journal of Speech and Hearing Research, 1963, 6, 369-378. 
ShatTuCK, S., \& Lackner, J. Speech production: Contribution of syntactic structure. Perceptual and Motor Skills, in press.

Silverman, S. I. Oral physiology, St. Louis: Mosby, 1961.

Sussman, H. M. What the tongue tells the brain. Psychological Bulletin, 1972, 77, 252-272.

Woodworth, R. S. The accuracy of voluntary movement. Psychological Review, 1899, 3, 1-114.

Yates, A. J. Delayed auditory feedback. Psychological Bulletin, $1963,60,213-233$

\section{NOTES}

1. Experiments in progress have revealed that strings of syntactically inflected nonsense words read with sentence intonation can be spoken with the same durational accuracy as normal sentences with the same number of "words" and syllables (Lackner, Note 3).

2. Lackner, J. Role of synatx in speech production. To be submitted for publication.
(Received for publication January 24, 1974; revision accepted October 3, 1974.) 